\title{
MORPHOLOGICAL AND STRUCTURAL CORNEAL CHANGES BY SOFT CONTACT LENSES IN MILD-MODERATE MYOPIA AFTER TWO WEEKS OF USAGE DISCONTINUATION.
}

\begin{abstract}
Purpose:
To evaluate the long-term effects of the soft contact lens (CL) on corneal curvature, corneal surface regularity, corneal thickness, corneal endothelium and tear break-up time in mild-moderate myopia comparing to the non-contact lens users myopic eyes, and to estimate the refractive and topographic alterations in myopic contact lens users (CLU) after two weeks cessation of wearing.

\section{Study design :}

A prospective, observational, and controlled study.
\end{abstract}

Methods:

The changes in topography, and pachymetry, corneal endothelium,

41

\section{$\mathscr{B}_{4}$}

Amani E Badawi, MD1.

\section{Fram}

${ }^{1}$ Lecturer of ophthalmology, Faculty of Medicine,

Mansoura University, Egypt

and TBUT were assessed in CLU group. The first pentacam evaluation was done within one day after CL removal (first visit) and then the second examination after two weeks from the cessation of $\mathrm{CL}$ (second visit). The topographical indices included keratometry readings in the flattest (K1), steepest meridians (K2), anterior maximum $\mathrm{K}$ reading ( $\mathrm{K}$ $\max )$, minimum $\mathrm{K}$ reading $(\mathrm{K} \min )$, Index of Surface Variance (ISV), keratoconus index $(\mathrm{KI})$, central and thinnest corneal thickness, endothelial count, Coefficient of variation (CV) and hexagonal \% were recorded each visit.

Results:

Following 2 weeks discontinuation of soft $\mathrm{CL}$, changes in $\mathrm{K}$ read-

MANSOURA MEDICAL JOURNAL 
ings, endothelial count, CV, hexagonal $\%$ seemed to be reversible, nevertheless, the changes in corneal thickness and TBUT appeared to require more time for resolving.

\section{Conclusions:}

Soft CL use is contributing to clinically substantial changes in topographical corneal parameters, corneal thickness, endothelial count, and TBUT. After 2 weeks of wearing discontinuations, these changes were reversible except corneal thickness and TBUT, which may need a longer time for recovery

Keywords: Soft contact lens, corneal curvature, Corneal endothelium, Myopia, Tear break up time.

\section{BACKGROUND}

Contact lenses $(C L)$ are still considered one of the preferred methods to correct refractive errors [1]. In spite of their effect in improving visual acuity and increasing visual field, they have significant disadvantages. It interferes with corneal physiology and metabolism and so changes the corneal curvature and refractive pattern even after discontinuation of contact lenses [2]. The time needed for resolving of these changes can differ according to lens material and shape [3]. It was found that both soft and Poly methyl methacrylate (PMMA) lenses cause corneal swelling but the soft lens had higher influence [4]. Thus, this study was designed to emphasize the long-term effects of the soft contact lens on corneal curvature, corneal surface regularity, corneal thickness using the pentacam tomography and corneal endothelial count using specular microscopy in mild-moderate myopia comparing to the non-contact lens users myopic eyes. As well as, it estimated the refractive and topographic alterations in myopic contact lens users (CLU) after two weeks cessation of wearing.

\section{SUBJECTS AND METHODS}

Study design

A prospective, observational, and controlled study.

\section{Subjects}

A consecutive series of contact lens users were enrolled prospectively in this study from March 2013 to April 2014. All participants were examined by the author. The inclusion criteria were mild to moderate myopia, wearing spherical soft con- 
tact lenses for more than 2 years at least 5 days per week, and aged 1835 years. Current ocular pathology, previous ocular surgery, dry eye, hard contact lens, toric or hyperopic contact lens users were excluded from the study. The control group (non-contact lens users) was included mild-moderate myopic candidates with no history of CL wear or any anterior segment abnormality. They also were matched the contact lens group as age and refractive errors.

\section{Methods}

All cohort participants underwent a detailed ophthalmic examination that consisted of best corrected visual acuity, slit-lamp biomicroscopy, auto Ref-Keratometer, tear film break-up time (TBUT) evaluation, intraocular pressure measurement, and fundus examination to rule out the possibility of retinal diseases or glaucoma. Corneal topography, pachymetry and endothelial count were assessed. Duration of lens wear, type of contact lens, and contact lens wearing time (hours /day) of all patients were also reported.

Tear film break-up time (TBUT) evaluation:
The TBUT was assessed using sterile sodium fluorescein eye drops which were instilled into the patient's conjunctival sac. To ascertain a homogeneous distribution of the stain, the subjects were firstly advised blinking fully and repeatedly for few seconds. Then they were instructed to refrain blinking till the end of the test. The corneal surface was examined under a slit-lamp microscope with a cobalt-blue filter (broad beam) which will be adjusted on 10x magnification and maximum illumination. The time that elapses between the last fully blinking and the appearance of the first dry black corneal spot was measured and recorded. It was assessed 3 times, and the mean reading values were listed. Less than 10 seconds was considered abnormal.

\section{Pentacam tomography:}

The changes in topography, and pachymetry were evaluated using Pentacam HR (Oculus, Wetzlar, Germany) in a windowless dim investigating room. The first pentacam evaluation was done within one day after CL removal (first visit) and then the second examination after two weeks from the ceasing of CL (sec-

MANSOURA MEDICAL JOURNAL 
ond visit). The topographical indices included keratometry readings in the flattest (K1), steepest meridians (K2), anterior maximum $\mathrm{K}$ reading ( $\mathrm{K}$ max), minimum $K$ reading ( $K$ min), Index of Surface Variance (ISV), keratoconus index $(\mathrm{KI})$ and central and thinnest corneal thickness were recorded each visit.

\section{Corneal endothelial count:}

It was estimated using a (Tomy EM-3000) noncontact specular microscopy and the results were collected each visit and compared. All Pentacam and endothelial count measurements in the current study were taken during normal clinic hours $(9: 00 \mathrm{am}$ to $3: 00 \mathrm{pm})$ to avoid the prejudice of diurnal variation effect on corneal readings. Informed consent to use the data in the research was signed by all participants.

\section{Statistical analysis}

Statistical analysis was performed with SPSS program version 17. Firstly, the collected data was tested for the normal distribution then it expressed in mean values. One way analysis of variance (ANOVA) test was performed to compare between the control eyes and the soft contact lens users eyes. The $P$ value of less than 0.05 was considered statistically significant.

\section{RESULTS}

Total number included in this prospective study was 42 eyes of 22 contact lens users and 46 eyes (23 cases) were controls. All participants were Egyptians. The mean age of the CL users was $23.17 \pm 5.34$ and of controls were $23.26 \pm 4.23$ years. There was a predominance of females $(81.82 \%)$ in the contact lens user group. The mean spherical error in CL users was $-4.02 \pm 1.56 \mathrm{D}$ and the control group was $3.89 \pm 1.34 \mathrm{D}$. The mean duration of contact lens wear was $3.75 \pm 5.19$ years (range 2- 11 years). The mean wearing time was $8.02 \pm 2.21$ hours per day (range $3-12$ hours) for $6.3 \pm$ 1.2 days per week (range 4- 7 days). Types of lenses used by participants were: Bausch \& lomb : Optima, Flexcon; and Freshlook.

Topographic and Pachymetry results:

The Mean of K1 \& K2 and maximum $\mathrm{K}$ were found slightly steeper in eyes of contact lenses users at first visit $(42.89 \pm .93 \mathrm{D}, 42.07 \pm .35 \mathrm{D}$, 
43.94 \pm 1.35 respectively) (Figure1). to normal controls (Figure 2) and the After cessation of the soft $C L$ for 2 difference was statistically significant weeks, the mean $\mathrm{K} 1$ became $42.07 \pm$ even after discontinuation of CL. Ta$.35 \mathrm{D}, \mathrm{K} 2$ was $43.04 \pm .97 \mathrm{D}$, and $\mathrm{K}$ ble (1)

max was $43.94 \pm 1.35$ with statistically non-significant difference compared to control group $(\mathrm{P}=.9621$, .8651 , and .2131 respectively).Table (1)

Compared to normal eyes, the eyes wearing contact lenses had significantly greater ISV and $\mathrm{KI}$ values $(P=.000)$. After 2 weeks, ISV only remained significantly high $(p=.0231)$. The mean central corneal thickness and thinnest location were reduced in contact lens users in comparison

The specular microscopy readings revealed a decrease in the mean endothelial cell density (ECD) in the CLU group which increased insignificantly after 2 weeks from wearing cessation with an insignificant difference from the controls $(p=.0741, . \quad 0712, .9241)$. Coefficient of variation (CV) and hexagonal \% readings showed insignificantly increase from the controls either in the first or the second visit. (Table 1) 
Table (1): Different studied corneal parameters in CLU (first and second visits) versus the controls:

\begin{tabular}{|c|c|c|c|c|c|c|}
\hline & $\begin{array}{l}\text { CL users } \\
\text { (first visits) } \\
\text { mean } \pm S D\end{array}$ & $\begin{array}{l}\text { P1 } \\
\text { Value }\end{array}$ & $\begin{array}{l}\text { CL users } \\
\text { (second } \\
\text { visit) } \\
m e a n \pm S D\end{array}$ & $\begin{array}{l}\text { P2 } \\
\text { Value }\end{array}$ & $\begin{array}{l}\text { Controls } \\
\text { mean } \pm S D\end{array}$ & $\begin{array}{l}\text { P3 } \\
\text { Value }\end{array}$ \\
\hline K1(D) & $42.89 \pm .93$ & $.000 *$ & $42.07 \pm .35$ & $.000^{*}$ & $42.06 \pm 1.14$ & .9621 \\
\hline K2 (D) & $43.64 \pm .97$ & $.000^{*}$ & $43.04 \pm .97$ & $.000 *$ & $43.02 \pm 1.40$ & .8651 \\
\hline $\mathrm{K} \max (\mathrm{D})$ & $44.84 \pm 1.22$ & $.000^{*}$ & $43.94 \pm 1.35$ & $.001 *$ & $43.45 \pm 1.04$ & .2141 \\
\hline $\mathrm{K} \min (\mathrm{D})$ & $41.64 \pm 1.32$ & $.002 *$ & $41.05 \pm 0.59$ & $.001 *$ & $41.01 \pm 0.59$ & .4251 \\
\hline ISV & $27.23 \pm 2.15$ & $.000^{*}$ & $20.05 \pm 2.24$ & $.000^{*}$ & $18.85 \pm 3.18$ & $.0231^{*}$ \\
\hline KI & $1.03 \pm 0.02$ & $.000^{*}$ & $0.95 \pm 0.12$ & $.000^{*}$ & $0.91 \pm 0.12$ & .0514 \\
\hline $\begin{array}{l}\text { CCT } \\
\text { (Micron) }\end{array}$ & $526.23 \pm 25.40$ & $.000^{*}$ & $540.74 \pm 35.40$ & $.000^{*}$ & $551.60 \pm 28.10$ & $.0142 *$ \\
\hline $\begin{array}{l}\text { Thinnest } \\
\text { (Micron) }\end{array}$ & $518.12 \pm 17.11$ & $.000^{*}$ & $531.56 \pm 22.3$ & $.000^{*}$ & $544.44 \pm 20.1$ & $.001^{*}$ \\
\hline $\begin{array}{l}\text { ECD } \\
\left(\text { cells } / \mathrm{mm}^{2}\right)\end{array}$ & $2979 \pm 272.12$ & .0741 & $3012 \pm 285.33$ & .0712 & $3019 \pm 253.41$ & .9241 \\
\hline CV & $39.02 \pm 2.23$ & .2540 & $38.57 \pm 2.15$ & .2611 & $38.54 \pm 3.12$ & 0.8432 \\
\hline $\begin{array}{l}\text { Hexagonal } \\
\text { cells \% }\end{array}$ & $58.84 \pm 2.33$ & .0741 & $58.63 \pm 2.41$ & .0712 & $58.55 \pm 2.07$ & .9241 \\
\hline TBUT & $8.17 \pm .85$ & $.000 *$ & $10.03 \pm .94$ & $.000 *$ & $13.23 \pm 1.1$ & $.000 *$ \\
\hline
\end{tabular}

SD: standard deviation; K1: keratometry readings in the flattest meridian; $K 2: K$ reading in steepest meridian $K$ max: maximum K reading; K min: minimum $K$ reading; ISV: Index of Surface Variance; KI: keratoconus index; CCT: Central corneal thickness; ECD: endothelial cell density; $C V$ : coefficient of variation, TBUT: Tear breakup time.

Test used: One way ANOVA, P significance at value $<0.05$.

P1: Significance between CLU in first and second visits.

P2: Significance between $C L U$ in first visit and the controls

P3: Significance between $C L U$ in second visit and the controls

Vol. 44, No. 1 \& 2 Jan. \& April, 2015 


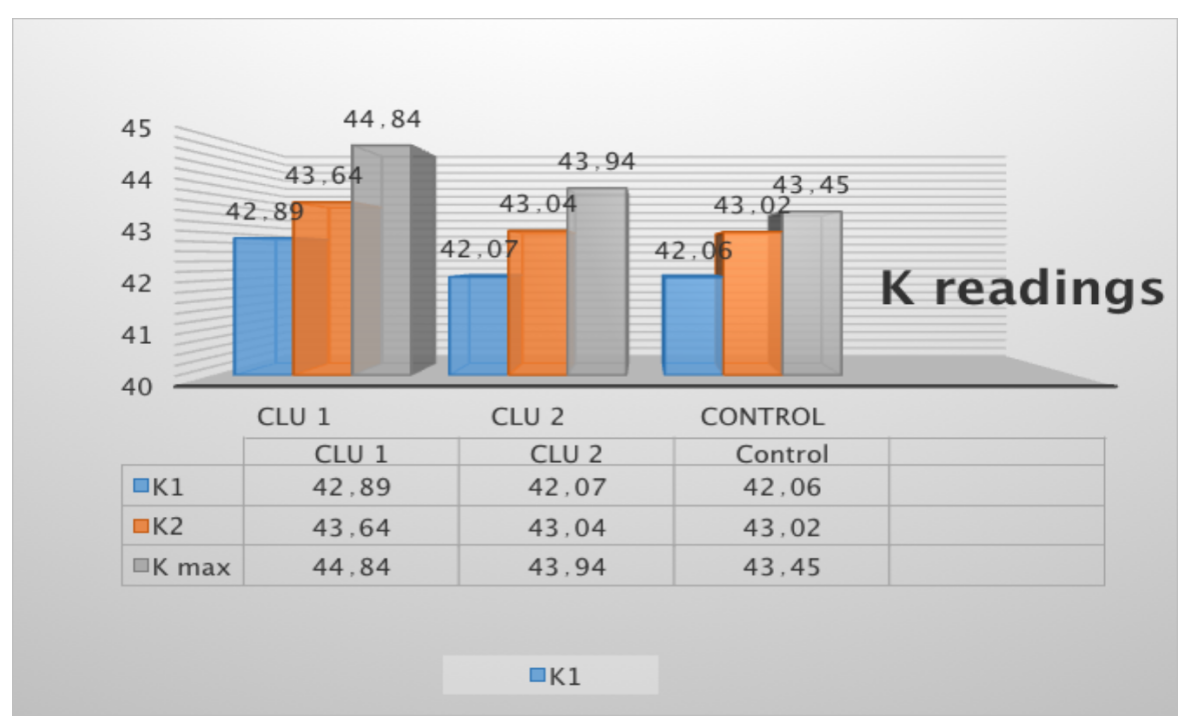

Figure (1): Keratometry (K) readings in CLU in (first \& second visit) and the control group. CLU1: Contact lens users in first visit, CLU2: Contact lens users in second visit; $\mathrm{K} 1$ : keratometry readings in the flattest meridian; $\mathrm{K} 2$ : $\mathrm{K}$ reading in steepest meridian $\mathrm{K}$ max: maximum $\mathrm{K}$ reading.

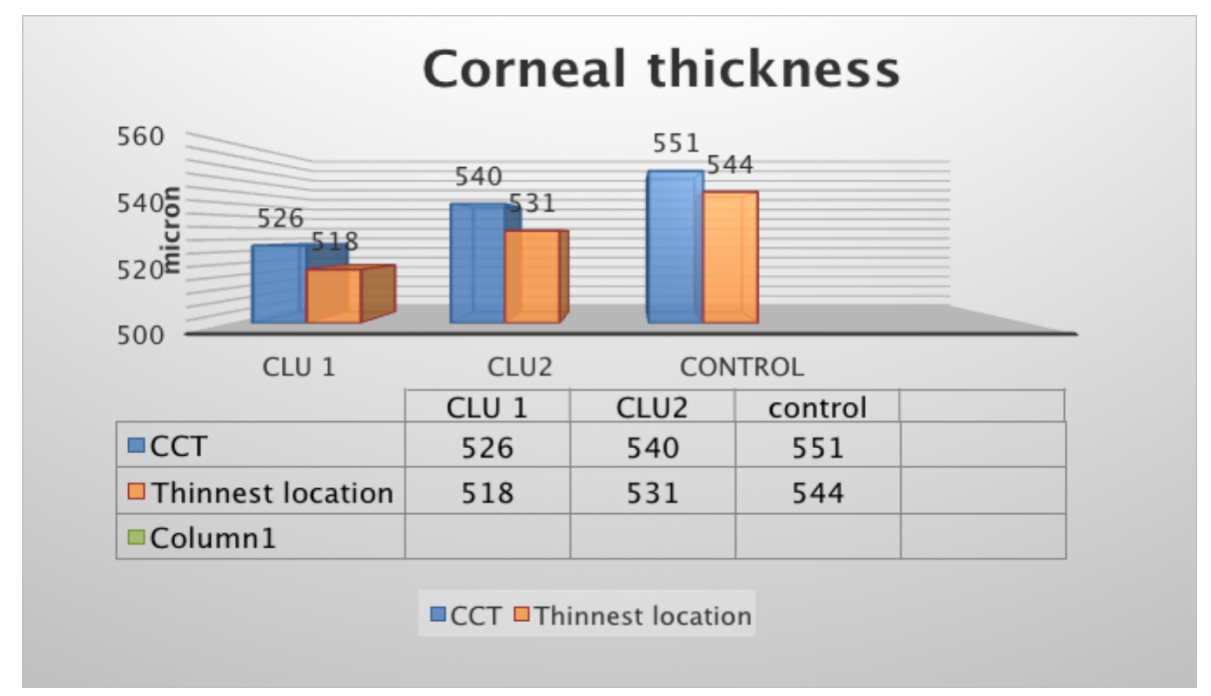

Figure (2): Corneal thickness in CLU in (first \& second visit) and the control group. CLU1: Contact lens users in first visit, CLU2: Contact lens users in second visit; CCT: central corneal thickness.

MANSOURA MEDICAL JOURNAL 


\section{DISCUSSION}

Alteration of the corneal shape and topographic pattern was recorded with many species of CL. Produced hypoxia, corneal swelling, and chronic mechanical trauma might be contributing factors [5].

In the current study, CLU eyes showed steeping in $\mathrm{K} 1, \mathrm{~K} 2, \mathrm{~K}$ max which improved after 2 weeks to reach values near to the controls with insignificant differences. Current results were in agreement with the other study $[1,6,7,8]$. While other reported flattening effect of contact lenses [9], or even no influence on keratomeric readings $[10]$.

Though corneal warpage is predominately associated with rigid $\mathrm{CL}$, many cases were reported to be related to soft $\mathrm{CL}$ (about $27.5 \%$ of all) $[6,11]$. Normal regular oxygenation of human cornea is acquired chiefly from atmospheric oxygen. Throughout CL wearing, the corneal tissue is oxygenated less than the normal level. Therefore, the induced hypoxia may be an attributed factor of such stepping [12].

The required time for recovery of $C L$ effects could be variable from 1 week up 2 months [6]. Currently, 2 weeks were sufficient to abolish the $\mathrm{CL}$ effect on kearometric shift which was comparable with other study findings [13].

Corneal pachymetry is a decisive parameter taken into consideration during any corneal refractive surgeries [14]. Consequently, measurement of corneal thickness in CL users is indispensable. Particularly for those who intend performing refractive surgeries. The present study demonstrated significant changes in corneal thickness resulted from $\mathrm{CL}$ and still statistically significantly lower than the control group values after two weeks since stopping of lens wearing. Gonzalez-Meijome and his colleagues stated the same results with recovery time 3 months [15].

Many prior studies reported such decline in the corneal thickness as a long-term effect of both soft and rigid $C L[16,17]$. While other reports showed that, the rigid $C L$ had a greater effect in corneal thickness reduction than the soft ones [1, 8]. These variations in the results can be traced to the use of various lens types and different study designs. 
An insignificant decrease of ECD was reported in CLU eyes compared to the control eyes. It still reduced insignificantly after 2 weeks. Regarding $\mathrm{CV}$ in their values and hexagonal $\%$, there was a trivial increase. These results were in agreement with other pervious researches [18, 19]

Also, the current study showed a significant shorting of TBUT in soft contact lens users. The TBUT remained lower than the control eyes after 2 weeks of lens discontinuation with a significant difference. Many studies were stated the strong association between $C L$ and the dry eye symptoms $[20,21]$. It was hypothesized that the CL had a negative impact on tear film stability, and it led to a separation of the tear film to 2 layers with an increase in its vaporization [22, 23]. As well as, contact lens might cause an alteration in meibomian glands structures with induced tear hyperosmolarity and instability [21].

\section{Limitations}

The study results may be of interest for the clinical application concerned the refractive surgeries, however, the small sample size and the lack of comparison between different lens materials may impact negatively on the results concluded from this study. Further researches with a larger sample size will be needed to support the current results

\section{CONCLUSION :}

Continued soft CL use is correlating to clinically substantial changes in topographical corneal parameters, corneal thickness, and reduction in TBUT. This effect seems to be a consequence of mechanical stress and induced hypoxia. The effect of contact lens wearing on the corneal endothelium was negligible. After 2 weeks of wearing discontinuations, these changes were reversible except corneal thickness and TBUT, which may need a longer time for recovery.

\section{Disclosure:}

No conflicts of interest in this work.

\section{REFERENCES}

1. Liu Z, Pflugfelder SC. (2000) : The effects of long term contact lens wear on corneal thickness, curvature and surface regularity.

MANSOURA MEDICAL JOURNAL 
Ophthalmology; 107:105111.

2. Hashemi, H., et al., (2008) : Corneal stability after discontinued soft contact lens wear.British Contact Lens Association, (31): 122-125.

3. Nourouzi, H., J. Rajavi, and M. (2006) : Okhovaatpour, Time to resolution of corneal edema after long-term contact lens wear. American Journal of Ophthalmology,. 142(4): 671-673.

4. Moezzi A Fonn D, Simpson T L, SorbaraL. (2004) : Contact Lens- Induced Corneal Swelling and Surface Changes Measured with the Orbscan II Corneal Topographer. Optometry and vision science; 81:18993.

5. Leung BK, Bonanno JA, Radke CJ. (2011) : Oxygendeficient metabolism and corneal edema. Prog Retin Eye Res.; 30(6):471-492.

6. Schornack M. (2003) : Hydrogel contact lens-induced corneal warpage. Cont Lens Anterior Eye.; 26(3):153159.

7. González-Méijome JM, González-Pérez J, Cerviño A, Yebra-Pimentel E, Parafita MA. (2003) : Changes in corneal structure with continuous wear of high-Dk soft contact lenses: a pilot study. Optom Vis Sci. Jun;80(6):440446.

8. Yeniad B, Yigit B, Issever $H$, KozerBilgin L. (2003) : Effects of Contact Lenses on Corneal Thickness and Corneal Curvature During Usage, Eye \& Contact Lens; 29(4): 223-229.

9. RP Sah , N Paudel, M Chaudhary, P Adhikari, SK Mishra. (2014) : The effects of soft contact lens wear on corneal thickness, curvature and surface regularity. Journal of Chitwan Medical College; 4(8): 3539. 
10. Sahin OG and Koç E. (2013 : Investigation of the Effects upon Keratometry by Second Generation Silicone Hydrogel Contact Lenses .British Journal of Medicine and Medical Research;3 (4) : 971-977.

11. Tseng, S., J. Hsiao, and D. (2007) : Chang, Mistaken diagnosis of keratoconus because of corneal warpage induced by hydrogel lens wear. Cornea,. 26: 1153-1155.

12. Leung BK, Bonanno JA, Radke CJ. (2011) : Oxygendeficient metabolism and corneal edema. Progress in retinal and eye research.; 30 (6):471-492.

13. Wang $X$, McCulley JP, Bowman RW, Cavanagh HD. (2002) : Time to resolution of contact lens-induced corneal warpage prior to refractive surgery. CLAO J., 28(4):169-171.

14. Joo C, Kim T. (2000) : Corneal ectasia detected after laser in situ keratomileusis for correction of less than -12 diopters of myopia. J Cataract Refract Surg; 26:292295.

15. Gonzalez-Meijome JM, Gonzalez-Perez J, Cervino A, Yebra-Pimentel E, Parafita MA. (2003): Changes in corneal structure with continuous wear high-Dk soft contact lenses, A pilot study. Optom Vis Sci, 80:440-446.

16. Holden B, Sweeney DF, Vannas $A$, et al. (1985) : Effects of long-term extended contact lens wear on the human cornea. Invest Ophthalmol Vis Sci; 26:1489501.

17. Bourne Wm, Holtan SB, Hodge DO. (1999) : Morphologic changes in corneal endothelial cells during 3 years of fluorocarbon contact lens wear. Cornea; 18; 1:29-3.

18. Lee JS, Park WS, Lee SH, Oum BS, Cho BM. (2001) MANSOURA MEDICAL JOURNAL 
52 MORPHOLOGICAL AND STRUCTURAL CORNEAL etc...

: A comparative study of cornealendothelial changes induced by different durations of soft contact lens wear.Graefes Arch Clin Exp Ophthalmol.; 239 (1):1-4.

19. Suzuki N, Okamura T. (2006) : [The effect of disposable contact lenses on the corneal endothelium]. Nippon Ganka Gakkai Zasshi.;110 (7):511-519.

20. Nichols JJ, Ziegler C, Mitchell GL, Nichols KK. (2005) : Self-reported dry eye disease across refractive modalities. Invest Ophthalmol Vis Sci.; 46(6):1911-1914.

21. Nichols JJ, Sinnott LT. (2006)
: Tear film, contact lens, and patient-related factors associated with contact lens-related dry eye. Invest Ophthalmol Vis Sci.; 47 (4):1319-1328.

22. Glasson MJ, Stapleton F, Keay L, Willcox MD. (2006) : The effect of short term contact lens wear on the tear film and ocular surface characteristics of tolerant and intolerant wearers. Cont Lens Anterior Eye.; 29(1):41-47.

23. Fonn D. (2007) : Targeting contact lens induced dryness and discomfort: what properties will make lenses more comfortable. Optom Vis Sci; 84(4):279-285. 